\title{
Topical Polydeoxyribonucleotide Loaded in Hydrogel Formulation for Wound Healing in Diabetic Rats
}

\author{
Mariya Dmitriyeva ${ }^{1} \mathbb{D}$, Timur Suleimenov ${ }^{1} \mathbb{D}$, Daulet Yessenbayev ${ }^{1} \mathbb{D}$, Dulat Turebayev ${ }^{1}$ D, Saltanat Urazova ${ }^{2} \mathbb{D}$, \\ Mirsaid Izimbergenov ${ }^{1}$ (D) Saken Kozhakhmetov ${ }^{1}$ (D), Talgat Omarov ${ }^{3}$ (D), Medet Toleubayev ${ }^{1}$ (iD) \\ ${ }^{1}$ Department of Surgery, Astana Medical University, Astana, Kazakhstan, Central Asia; ${ }^{2}$ Department of General Medicine, Astana \\ Medical University, Kazakhstan, Central Asia; ${ }^{3}$ Department of Pathology, Astana Medical University, Kazakhstan, Central Asia
}

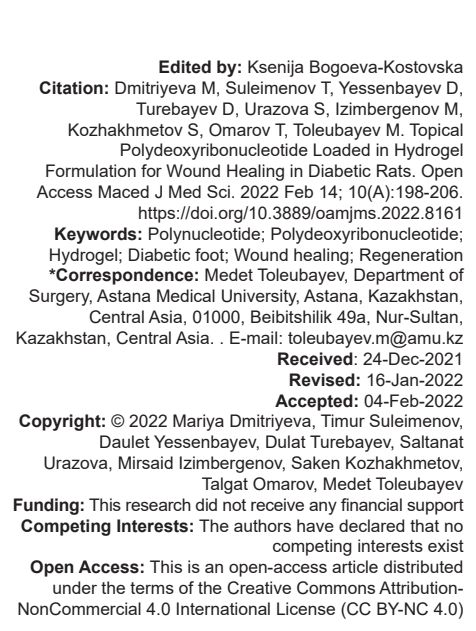

\section{Introduction}

Diabetic foot complications represent a major health burden and drain on resources [1]. It led to the development of several new treatments in the context of the increasing number of patients with chronic wounds and represents the next challenge [2], [3]. Lack of cellular and molecular signals required for normal wound-repair process such as angiogenesis, granulation tissue formation, epithelialization, and remodeling may be a major contributing factor to the poor healing of diabetic wound [4], [5], [6]. It is known that high blood glucose concentrations disrupt the function of granulocytes and neutrophils, as well as chemotaxis, which leads to an increased risk of infection and impaired wound healing [7], [8], [9], [10] not only due to impaired internal healing functions, but also due to the disordered participation of cellular components wound healing, moreover, in hyperglycemia, the balance between proangiogenic and anti-angiogenic regulators is disturbed and leads to inadequate angiogenesis [11]
Polydeoxyribonucleotide (PDRN) is a DNA extracted from the sperm cells of Oncorhynchus mykiss (Salmon trout) or Oncorhynchus keta (Chum Salmon) with a molecular weight ranging from 50 to $1500 \mathrm{kDa}$ [12] and it is known to degrade by unspecific DNA nuclease then excreted by urine or feces. PDRN is known to have many positive therapeutic effects such as improving angiogenesis [8], [13], [14], increasing collagen synthesis [15], having an anti-inflammatory activity [16], and angiogenic effects and to accelerate wound healing [17]. PDRN is known to have and angiogenic effects and to accelerate proliferation of fibroblasts and could improve peripheral tissue oxygenation and angiogenesis in diabetic foot ulcers, to improve wound healing [18]. Topical application techniques present the PDRN loaded in biodegradable hydrogel, sustained, and localized delivery in addition to protect the PDRN from enzymatic degradation [19], [20], [21]. To combine sustained release and PDRN localization at the lesion site, a drug-delivery system composed of PDRN loaded within a carboxymetilcellulose hydrogel was selected [22]. It has been widely used for drug 
delivery vehicle due to its biocompatibility, low toxicity, and relatively low cost. The application of PDRN in diabetic tissue regeneration has already been proven to be beneficial, with a stimulatory effect on cell proliferation and new blood vessel formation. However, its application and delivery through a hydrogel vehicle have not yet been well defined.

We hypothesized the delivery of PDRN loaded in hydrogel directly application on diabetic wound and provide functional recovery [23], [24], [25], [26]. The objectives were then to: (1) Evaluate the influence of PDRN from carboxymetillcelulose (CMC) hydrogel; (2) evaluate quantitative analysis of diabetic wound size after PDRN loaded in hydrogel topical treatment; and (3) study the histopathological examination of rat diabetic wound sample, measurement number of fibroblasts, collagen fibers, and average number of blood vessels in a diabetic rat wound model within the 21 days of study.

\section{Methods}

The study has been carried out along the "Principles of laboratory animal care" (NIH Publication no. 85-23, revised 1985), and according to the national law, if applicable [27].

\section{Preparation of PDRN loaded in hydrogel}

PDRN is the liquid substance in prefilled syringe and capacity $2 \mathrm{mg} / \mathrm{ml}$ deoxyribonucleic acid 250-350 kDa, Yuma Medical, UK, Scotland.

Comfeel Purilon $®$ Gel, $15 \mathrm{~g}$, is a sterile hydrogel and consists of purified water, sodium CMC, and calcium alginate, Coloplast, Denmark.

Five PDRN-hydrogel compositions were prepared with different ratios, in the 5:1 hydrogel and PDRN relation, full diffusion of PDRN into the hydrogel in $12 \mathrm{~h}$ is observed. The PDRN release from the selected hydrogel compositions was determined through agar diffusion test. PDRN loaded in hydrogel was prepared with $v / v$ ratio $1: 5$, while the maximum PDRN time diffusion from hydrogel was $72 \mathrm{~h}$, this determines the application PDRN interval on the wound during the study.

\section{Creation of the animal experimental model}

For this experiment, 60 4-month-old male Wistar nude rats with a weight of 300-400 g (360 g on average) were used. They underwent a 1-week adaptation period while being bred, fed, and given water at the laboratory. All animal procedures were performed according to the Guide for the Care and Use of Laboratory Animals of the University Animal Care Committee. The clearance to conduct this study was provided by the Medical University Astana Committee of Animals and Ethics (Protocol № 6).

All animals $n=60$ were given an intraperitoneal injection of alloxan monohydrate in a dosage of $150 \mathrm{mg} / \mathrm{kg}$. On the $7^{\text {th }}$ day after that, 36 rats with persistent glycemia $>11 \mathrm{mmol} / \mathrm{L}$ (14.1 $\mathrm{mmol} / \mathrm{l}$ on average) were taken in the experiment.

Creating of a full-layer skin wound was carried out under conditions of inhalation anesthesia; $3 \mathrm{mg} / \mathrm{kg}$ of Sevorane and $250 \mathrm{ml}$ (Abbott Laboratories, UK) were used. After the removal of the hair in the dorsum of each rat using an electroepilator, the dorsum was disinfected with $0.05 \%$ chlorhexidine and circular wound was drawn in the head side, with a no. 15 blade and fine scissors, a full-thickness skin defect wound was made, the diameter of each wound was $180 \mathrm{~mm}$ on average. Each animal was kept in a solitary cage to prevent the wounds from being eaten by other animals. Therefore, a total of 36 wounds ( $n=12$ per group) were created (Figure 1).

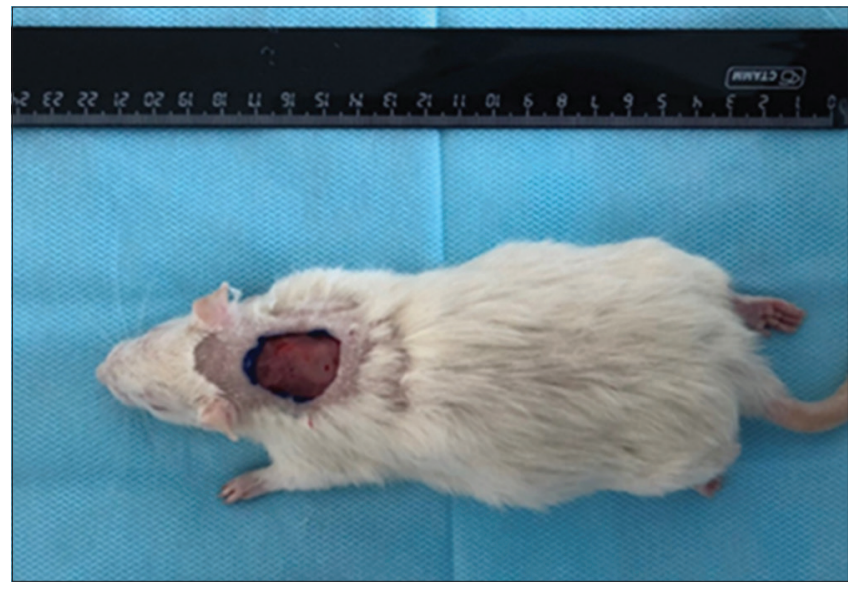

Figure 1: Skin defects in the diabetic rat model

\section{PDRN application and treatment}

The 36 rats were divided into three treatment method groups: The control group of 12 rats, to which neither PDRN nor hydrogel was applied, a hydrogel only group of 12 rats, and a group of 12 rats, to which PDRN loaded in hydrogel was applied. The dressing was replaced every 3 days and the wounds were photographed on days $3,7,14$, and 21 to assess their size.

For the hydrogel-only group, about $1 \mathrm{~mL}$ of hydrogel was applied locally. In the PDRN/hydrogel combined-treatment groups, $0.2 \mathrm{~mL}$ of PDRN loaded in $1 \mathrm{~mL}$ of hydrogel was applied locally on the base of each wound using a 2-mL syringe (Figure 2). Each wound was dressed using Opsite (Smith and Nephew, London, UK) and the dressing was fixed with Surgifix (Panamedic). Each rat was placed in a separate cage and observed for 3 weeks. 


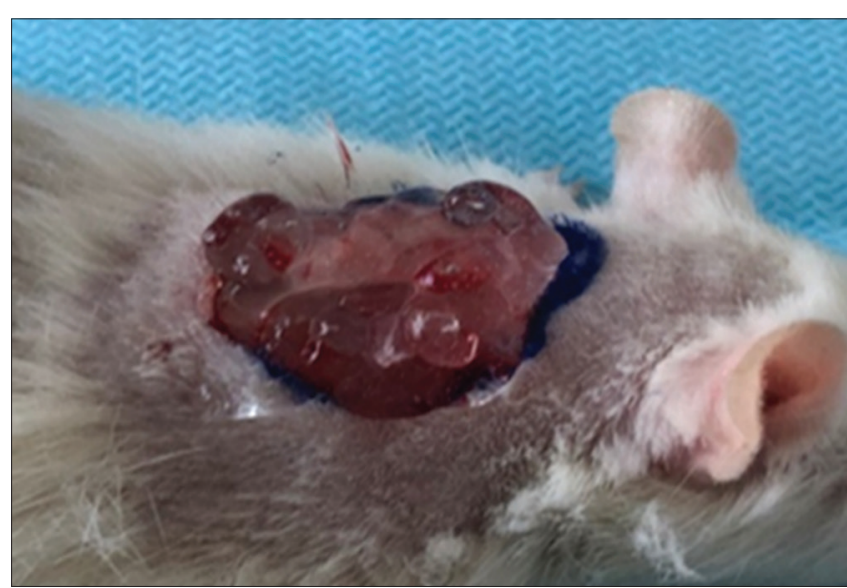

Figure 2: Application of Polydeoxyribonucleotide loaded in hydrogel

\section{wound size \\ Visual examination and measurement of}

After the creation of the wound, the dressing was replaced every 3 days and photos of the wound were taken on days $3,7,14$, and 21 at the same resolution and distance using a digital single-lens reflex camera (Nikon D5600, Tokyo, Japan). The quantitative assessment of the wound size based on the edge of the epithelialized portion and was determined by applying graph paper and calculated in $\mathrm{mm}^{2}$. Total reduction in the wound size was calculated by dividing the surface area at each time point to that of the original wound using the formula: Total wound constriction $(\%)=(($ wound surface area/original wound surface area) $\times 100$ ).

\section{Histopathology}

On days $3,7,14$, and 21 , three rats were sacrificed, respectively, and 12 specimens were collected from each group. The samples, including about $1.2 \mathrm{~mm}$ of normal skin from the edge of the wound (including the epithelialized portion), were resected with a no. 15 blade. After resection of the center of the wound, hematoxylin and eosin ( $\mathrm{H}$ and $\mathrm{E}$ ) staining was applied. The collected samples were stored by freezing them at $-70^{\circ} \mathrm{C}$ and fixed in $10 \%$ formalin for 1 day to produce histopathology slides. Thereafter, paraffin embedding was performed, the specimens were sliced into 4- $\mu \mathrm{m}$-thick parts, and $\mathrm{H}$ and $\mathrm{E}$ staining was applied to produce tissue sample slides. Microscopy and microphotography of histological preparations were performed on an Olympus complex. Using the method of spot counting, the ratio of cells in the infiltrate or in the composition of granulation tissue was also determined. Cells were counted - we list which cells in ten random fields of view per 100 cells. Quantitative indicators were expressed in \%.

Counting the number of structural elements of tissue, such as blood vessels and connective tissue fibers were observed with a microscope in each of the different fields of three sites for each slide, at $\times 100$ magnification in absolute values in ten random fields of view. Histologically determined macroscopic and morphological descriptions of wound preparations in groups at all stages of the study, average number of fibroblasts, collagen fibers, and blood vessels.

\section{Statistical analysis}

To compare the wound sizes, change rates, and numbers of fibroblasts, collagen fibers and blood vessels at the different time points per group $(3,7,14$, and 21 days), two-way repeated-measures analysis of variance (ANOVA) was conducted.

To determine if the difference between the groups at each time point was significant, ANOVA tests were performed at each time point, the Tukey honest significant difference test was used for paired comparison between groups. Data were expressed as the mean \pm standard deviation for each group of animals. All statistical analysis was conducted using SPSS ver. 14.0KO (SPSS Inc., Chicago, IL, USA) and R 3.1.3 (R Foundation for Statistical Computing, Vienna, Austria) and the significance level was set at $\mathrm{p}<0.05$.

\section{Results}

\section{Quantitative analysis of wound size}

The initial wound sizes were similar across all groups. The wounds of the rats in the PDRN loaded in hydrogel treatment group on day 3 were smaller than those of the rats in the hydrogel-only and control group. On days 7,14 , and 21 , the same results were obtained, and on day 21 , wound healing was complete in the PDRN loaded in hydrogel group, while the wounds of the rats in the other groups remained. In the quantitative analysis, the differences in wound size between the PDRN loaded in hydrogel group and the two other groups on days $3,7,14$, and 21 were all significant $(p<0.05)$. The differences in the changes in the wound size were also significant $(p<0.05)$. For the PDRN loaded in hydrogel and hydrogel-only groups, the differences and changes in the wound size were significant on days 7,14 , and 21 and compared to the control group (Figure 3, Table 1).

\section{Histopathology}

The results of the analysis of the morphological changes dynamics in the skin wounds of the rats determined that the regression of alterative necrotic and exudative inflammatory changes occurs $2-3$ days faster in the bottom and at the edges of the wound defect in rats of the main group, in comparison with the control. Moreover, in the hydrogel-only treatment group 
and the PDRN loaded in hydrogel group on day 7 , zones of fibrinous necrosis are still preserved in the tissues of the wound defect in the rats of the control group (Figure 4). From the $14^{\text {th }}$ day of the experiment, signs of the predominance of reparative and proliferative processes develop in the bottom and edges of the skin wound of the main group of rats, more pronounced than in the control (Figure 5), on the $21^{\text {st }}$ day in the main group, a greater number of collagen fibers with a small vascular component are determined (Figure 6).

\section{Analysis of the fibroblasts and collagen}

\section{fibers}

The number of fibroblasts and collagen fibers was determined using an optical microscope and the changes were analyzed. After treatment, the differences of the average number of fibroblasts and collagen fibers in the three groups were found to be significant $(p<0.05)$.

In the PDRN loaded in hydrogel treatment group on the $3^{\text {rd }}$ day, the number of fibroblasts in the wounds exceeded these indicators in the control group. On the day 7, the PDRN loaded in hydrogel treatment group showed the highest value of fibroblasts compared to that of the control group. On the day 14 , the fibroblast

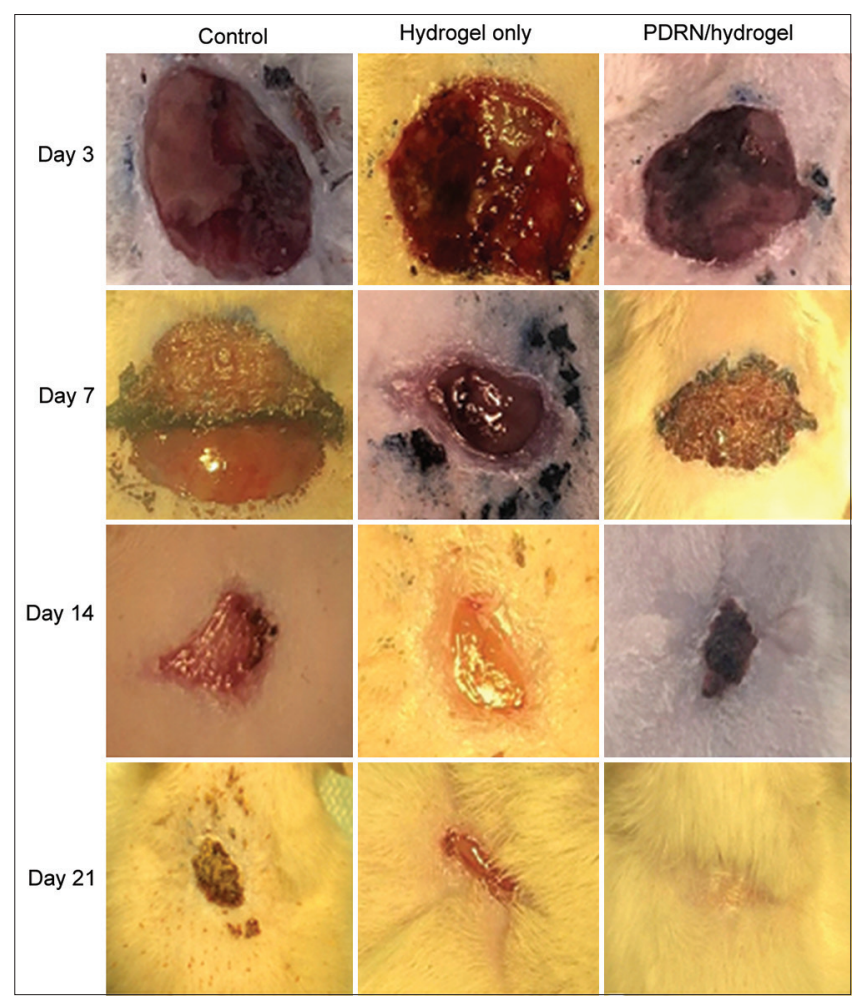

Figure 3: Gross appearance of the wounds rate in the PDRN loaded in hydrogel treatment group was significantly higher than in the control group and hydrogel-only treatment group. On day 21 , the average number of fibroblasts decreases in all groups, while the number of fibroblasts in the control group becomes more than in the PDRN loaded in hydrogel group and hydrogel only group (Table 2).

In the PDRN loaded in hydrogel treatment group, determined a gradual increase of collagen fibers with a peak of this indicator by day 21 , this index was significantly higher than in the control group and hydrogel only treatment group (Table 3).

\section{Measurement of the average number of blood vessels}

The number of blood vessels was determined using an optical microscope and the changes were analyzed. After treatment, the differences in the average number of blood vessels in the three groups were found to be significant $(p<0.05)$ and the increase in the number of blood vessels over time was found to be significant in all groups (Table 4).

In a comparison of the average numbers of blood vessels per area, the PDRN loaded in hydrogel treatment group showed significant differences on days 7 with a peak of this indicator that was significantly higher than in the control group and hydrogel only treatment group.

\section{Discussion}

In patients with diabetes mellitus, the wound healing process is impaired, which can increase the overall morbidity and mortality in this population [1]. Complex cellular and molecular processes, including inflammation, cell migration, angiogenesis, temporary matrix synthesis, collagen deposition, and re-epithelialization, characterize normal skin regeneration [7]. There is a complex cascade of events in skin repair, angiogenesis, and angiogenesis, which play a key role in wound healing and are associated with the expression of several cytokines and angiogenic factors [6], [28], [29], [30].

Previously, it was shown that PDRN, a compound containing a mixture of deoxyribonucleotide polymers of different lengths, is an agent that stimulates

Table 1: Comparison of wound sizes in all groups with time progression

\begin{tabular}{|c|c|c|c|c|c|c|}
\hline \multirow[t]{2}{*}{ Group } & \multicolumn{5}{|c|}{ Measurement $\left(\mathrm{mm}^{2}\right)$} & \multirow[t]{2}{*}{ Comparison ( $\mathrm{p}$-value) } \\
\hline & Day 0 & Day 3 & Day 7 & Day 14 & Day 21 & \\
\hline Control & $260.2 \pm 0.3$ & $198.1 \pm 1.2$ & $168.1 \pm 1.6$ & $27.7 \pm 1.0$ & $14.3 \pm 2.1$ & Group, $<0.05$ \\
\hline Hydrogel only & $251.1 \pm 0.3$ & $178.0 \pm 3.2$ & $35.0 \pm 1.8^{(\mathrm{a}, \mathrm{s})}$ & $19.9 \pm 1.6^{(a)}$ & $2.1 \pm 1.0$ & Time,$<0.05$ \\
\hline PDRN/Hydrogel & $259.9 \pm 0.3$ & $167.6 \pm 2.4^{(\mathrm{a})}$ & $51.1 \pm 3.2^{(a)}$ & $19.3 \pm 0.6$ & $0.5 \pm 0.4^{(2,6)}$ & Interaction, $<0.05$ \\
\hline
\end{tabular}




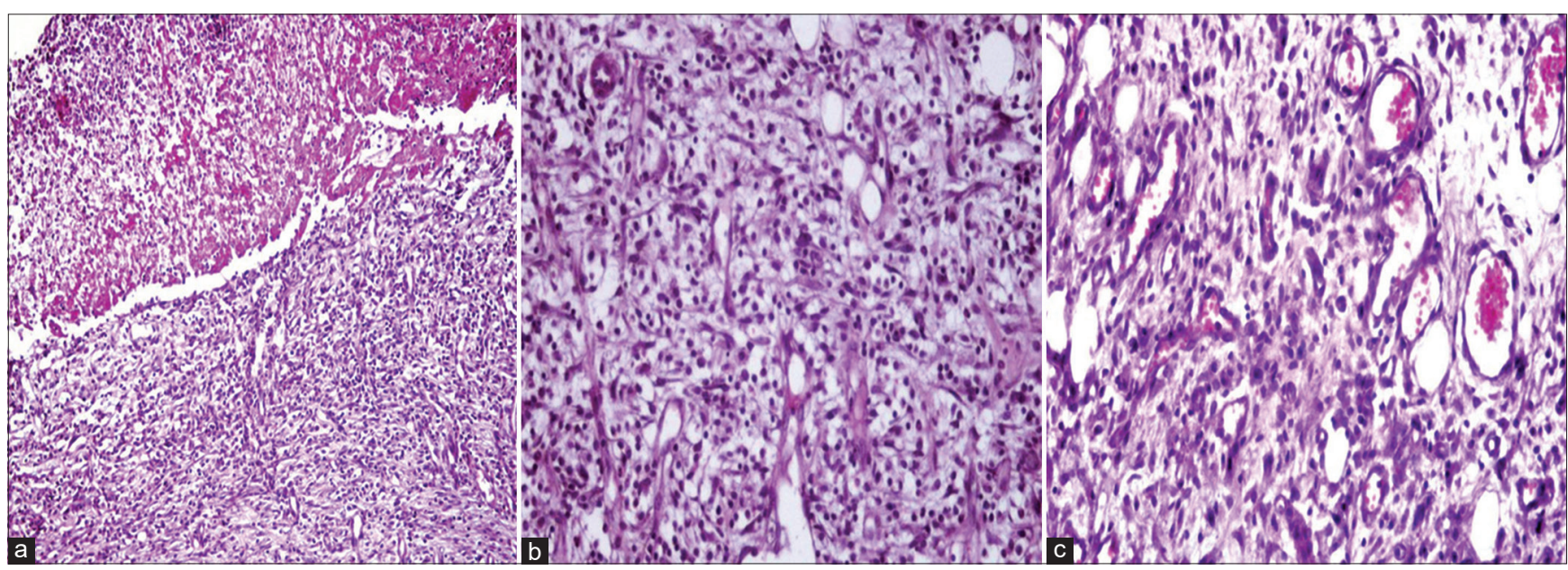

Figure 4: Histologic findings on day $7 \mathrm{H}$ and E, $\times 100$. (a) Control group. Areas of fibrinoid necrosis in combination with granulation tissue at the bottom of the wound. (b) Hydrogel only group. Signs of an increase in the number of fibrocytes in the field of view. (c) PDRN/Hydrogel group. Signs of an increase in the number of fibrocytes in the field of view

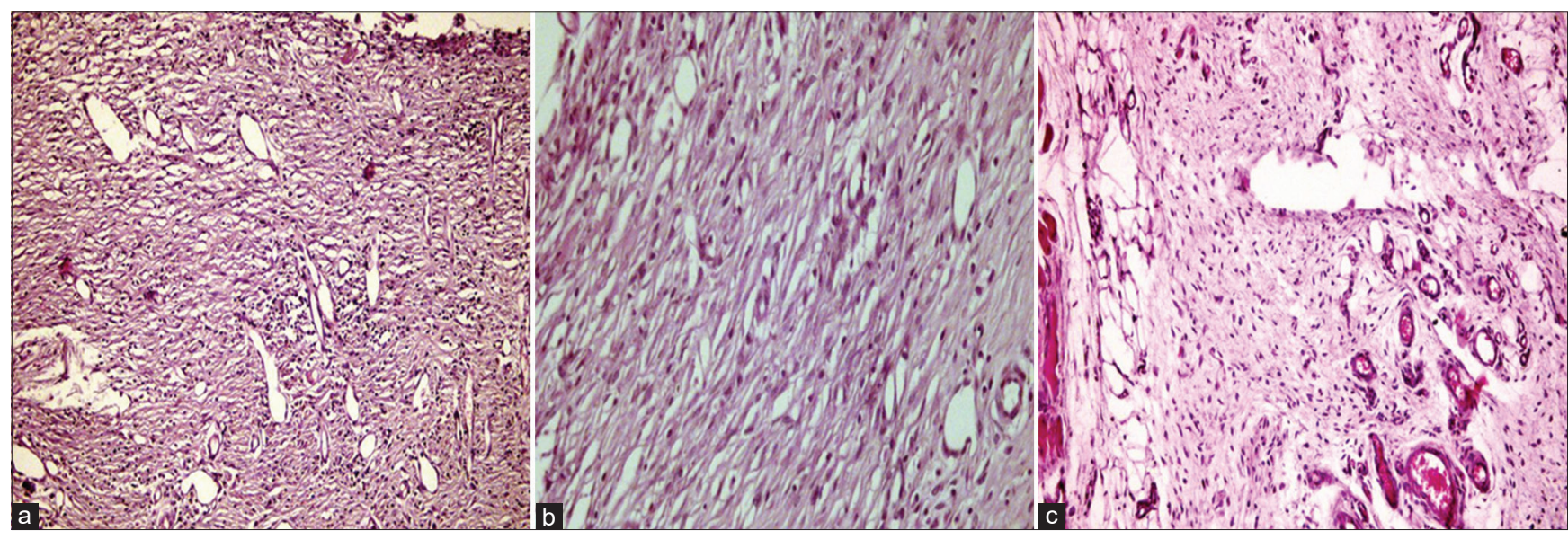

Figure 5: Histologic findings on day $14 \mathrm{H}$ and E, $\times 100$. (a) Control group. Focal lymphocytic infiltration with an admixture of leukocytes and areas of epidermis in loose fibrous connective tissue. (b) Hydrogel only group. Loose fibrous connective tissue with an admixture of single lymphocytes. (c) PDRN/Hydrogel group. Scattered fibrocyte infiltrates with an admixture of single lymphocytes

tissue repair in some pathology, providing a source of deoxyribonucleotides and deoxyribonucleosides, which can increase the proliferation and activity of cells of various tissues [31].
In general, PDRN derivatives may act as stimulators of fibroblast growth [18], [32] and angiogenic activity. All these data have prompted us to study the effect of PDRN on wound healing in diabetes [8], [10], [13], [14].

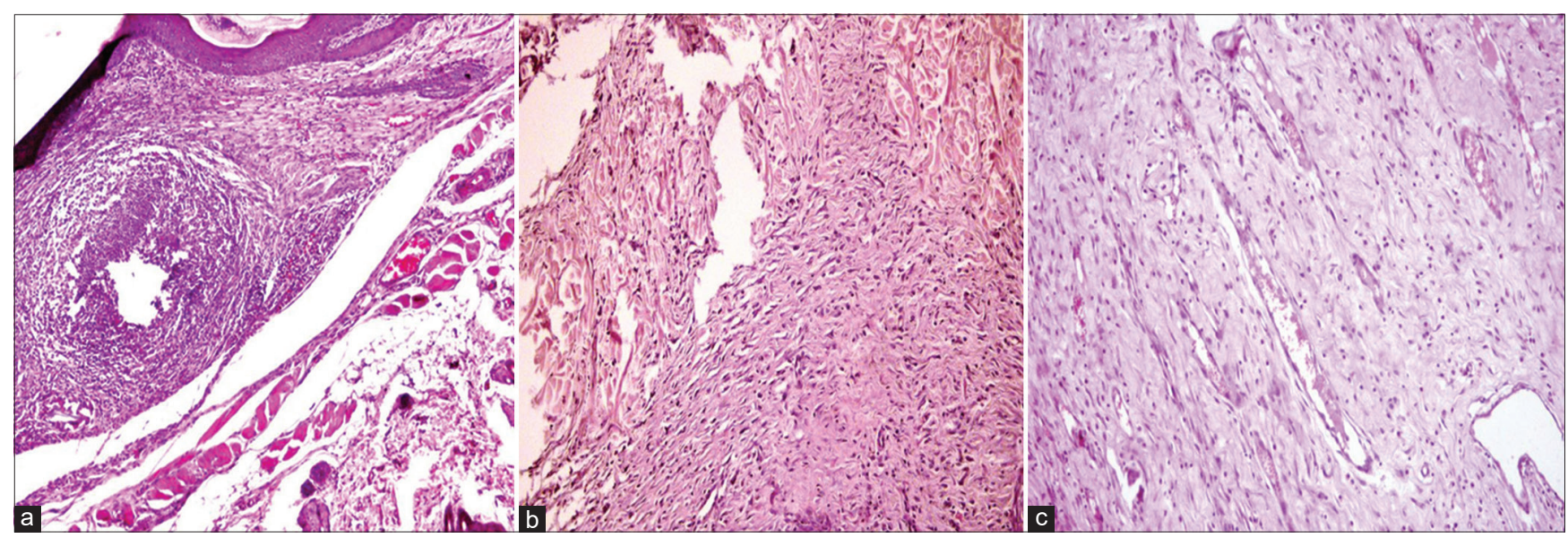

Figure 6: Histologic findings on day $21 \mathrm{H}$ and E, $\times 100$. (a) Control group. Microabscesses along the edge of the wound defect on the $21^{\text {st }}$ day. (b) Hydrogel only group. Areas of coarse-fibrous transformation in the thickness of loose-fibrous tissue on the $21^{\text {st }}$ day of the study. (c) PDRN/ Hydrogel group. Roughly fibrous connective tissue in the area of the bottom of the skin wound on the $21^{\text {st }}$ day 
Xi etal. in their investigated the effects of treating chronic ulcer in diabetic rats with a self-assembling nanofiber gel encapsulated with PDRN. Human embryonic fibroblast cells and vascular endothelial cells were treated with short poly-N-acetylglucosamine nanofibers and PDRN. Expression levels of cytokines and angiogenic factors increased in the treatment groups (mice with diabetic skin ulcer), especially in the sNAG-PDRN encapsulated group. The results showed that PDRN, sNAG, and sNAG-encapsulated-PDRN can improve wound healing, immunohistochemical results showed that PDRN, sNAG, and sNAG-encapsulatedPDRN promoted cell proliferation and new vessel formation, especially sNAG-encapsulated-PDRN [33].

Table 2: Comparison of the average numbers of fibroblasts per unit area

\begin{tabular}{llllll}
\hline \multirow{2}{*}{ Group } & \multicolumn{2}{l}{ Measurement $\left(\mathrm{mm}^{2}\right)$} & Comparison (p-value) \\
\cline { 2 - 5 } & Day 3 & Day 7 & Day 14 & Day 21 & \\
\hline Control & $5.1 \pm 0.3$ & $8.0 \pm 0.9$ & $16 \pm 1.2$ & $14 \pm 0.7$ & Group, $<0.05$ \\
Hydrogel only & $6 \pm 0.4$ & $16.4 \pm 1.1$ & $18.2 \pm 1.3$ & $13.6 \pm 0.7$ & Time, $<0.05$ \\
PDRN/Hydrogel & $5.7 \pm 0.4$ & $16.7 \pm 1.1$ & $21 \pm 1.6\left({ }^{*}\right)$ & $13 \pm 0.7$ & Interaction, $<0.05$ \\
\hline These results were derived through two-way repeated-measures ANOVA. Values are presented as mean \pm \\
standard deviation. $\left({ }^{*}\right)$ - Significant difference with the control group.
\end{tabular}

Altavilla et al. study was treated animal wounds with PDRN (PDRN, $8 \mathrm{mg} / \mathrm{kg} / \mathrm{ip}$ ). Proliferation of granulation tissue by immunostaining Ki67, cyclin D/CDK6 and cyclin E/CDK2 complexes, and p21 and p16 proteins (Western blotting), and histological changes was assessed on different days $(3,6$, and 12 days after injury).

Table 3: Comparison of the average numbers of collagen fibers per unit area

\begin{tabular}{llllll}
\hline Group & \multicolumn{3}{l}{ Measurement $\left(\mathrm{mm}^{2}\right)$} & Comparison (p-value) \\
\cline { 2 - 5 } & Day 3 & Day 7 & Day 14 & Day 21 & \\
\hline Control & 0 & $4.2 \pm 0.4$ & $15.3 \pm 0.8$ & $21.3 \pm 1.4$ & Group, $<0.05$ \\
Hydrogel only & 0 & $6.6 \pm 0.5\left(^{*}\right)$ & $16.7 \pm 0.9$ & $23.3 \pm 1.5$ & Time, $<0.05$ \\
PDRN/Hydrogel & 0 & $6.6 \pm 0.6\left({ }^{*}\right)$ & $17.6 \pm 1.2\left(^{*}\right)$ & $25.3 \pm 1.6\left(^{*}\right)$ & Interaction, $<0.05$ \\
\hline \multicolumn{7}{l}{ These results were derived through two-way repeated-measures ANOVA. Values are presented as mean \pm} \\
standard deviation. & $\left({ }^{*}\right)$ - Significant difference with the control group.
\end{tabular}

Numerous Ki67-positive cells were observed on days 3 and 6 in the granulation tissue of normoglycemic mice. Ki67-positive cells were fewer in diabetic mice than in normoglycemic mice. PDRN increased Ki67-positive cells in diabetic mice. Normoglycemic mice showed the greatest upregulation of cyclin D1, CDK6, cyclin E, and CDK2 at day 6. Diabetic mice had markedly lower expression of cyclin D1, CDK6, cyclin E, and CDK2 on day 6 , and $\mathrm{p} 15$ and $\mathrm{p} 27$ on day 6 . Administration of PDRN to diabetic mice increased the expression of cyclin D1/ CDK6 and cyclin E/CDK2 and decreased the inhibitors of p15 and p27 on day 6 after injury; in addition, it improved wound healing on the $12^{\text {th }}$ day. The results suggest that activation of the A2A adenosine receptor by PDRN may represent a therapeutic strategy for overcoming the diabetic-impaired cell cycle mechanism [34].

Table 4: Comparison of the average numbers of blood vessels per unit area

\begin{tabular}{|c|c|c|c|c|c|}
\hline \multirow{2}{*}{ Group } & \multicolumn{4}{|c|}{ Measurement $\left(\mathrm{mm}^{2}\right)$} & \multirow{2}{*}{$\begin{array}{l}\text { Comparison } \\
\text { (p-value) }\end{array}$} \\
\hline & Day 3 & Day 7 & Day 14 & Day 21 & \\
\hline Control & $15.9 \pm 0.8$ & $19.3 \pm 1.2$ & $11.2 \pm 0.7$ & $8.5 \pm 0.5$ & Group, $<0.05$ \\
\hline Hydrogel only & $18.0 \pm 0.8$ & $20.7 \pm 1.2$ & $12.4 \pm 0.8$ & $8.4 \pm 0.5$ & Time,$<0.05$ \\
\hline PDRN/Hydrogel & $18.6 \pm 0.9$ & $23.1 \pm 1.4^{*}$ & $12.9 \pm 0.7^{*}$ & $7.8 \pm 0.5$ & Interaction, $<0.05$ \\
\hline
\end{tabular}

Galeano et al. studied the effect of PDRN on diabetes-related healing defects using a post-operative cutaneous wound model created on the back of diabetic female mice. Animals were treated daily for 12 days with PDRN (8 mg/kg/ip) or vehicle $(100 \mathrm{ml} 0.9 \%$ $\mathrm{NaCl}$ ). PDRN injection in diabetic mice resulted in an increase in VEGF message and wound protein content on day 6. Impaired wound healing and increased force of wound tearing in diabetic mice. PDRN also produced a marked increase in CD31 immunostaining and induced the expression of transglutaminase-II and angiopoietin-1 [35].

Study of Kwon et al. confirmed the effects of PDRN and observed that PDRN stimulated closure of wounded monolayers of human fibroblast cells. PDRN $(8.25 \mathrm{mg} / \mathrm{ml})$ or phosphate-buffered saline $(0.9 \% \mathrm{NaCl})$ was injected once daily into the dermis adjacent to the wound of diabetic mice for 12 days after skin injury. Time course observations revealed that mice treated with PDRN showed accelerated wound closure and epidermal and dermal regeneration and enhanced angiogenesis. Histological evaluation showed an increase of vascular endothelial growth factor, CD31, and collagen fibers in the PDRN group compared with the control group [8].

Local application of PDRN can create the inconvenience that the concentration of PDRN can be unstable. To overcome this limitation and increase the duration of action and effect, a scaffold or carrier can be used together with a basic substance such as PDRN; in particular, this study was aimed at examining the effect when using a hydrogel as a base. A hydrogel generally refers to a three-dimensional, hydrophilic, high molecular weight, and reticular substance that can expand easily due to a significant degree of moisture. The hydrogel has received a lot of attention and has been widely discussed in the literature as a bandage. It is currently used in clinics [25].

It comes in various types, including amorphous hydrogel, hydrogel-impregnated gauze, and hydrogel sheet. The hydrogel dressing acts as a moisturizer, prevents crust formation by maintaining the water content of the wound, and promotes wound healing in the center [23], [36].

The hydrogel has a three-dimensional structure, absorbs secretions and foreign materials, and protects the space by expanding the cross-linking structure of the polymer chain. In addition, the hydrogel does not adhere strongly to the wound surface and does not cause irritation. It can also be removed easily without pain. The biodegradation and cell adhesion of the hydrogel can be controlled with excellent biocompatibility and it is mechanically suitable for use as a biologically applicable scaffold in a soft form. One study reported its use as a combination treatment with biological materials [26], [37].

Since the hydrogel has dual properties as a carrier or carrier due to its three-dimensional structure, 
the previous studies have noted its use to accelerate the healing of soft tissue and bone defects by adding other bioactive substances. Additives varied and include traditional antibiotics such as povidone iodine, collagen or antibiotics, PRP, PDRN, and stem cells [21]. The hydrogel used in this experiment was Purilon Gel (Coloplast), an amorphous gel composed of highly biocompatible natural materials such as purified water, sodium CMC, and calcium alginate; it applies to any type of wound. The increased size and number of blood vessels are some of the factors important for wound healing, as the blood vessels supply oxygen and nutrients to the tissues undergoing regeneration.

While PDRN wound healing effects had already been reported in the previous studies, this present research aimed to evaluate the efficacy of the PDRN/hydrogel compounds.

To date, there is sample evidence of the positive effect of PDRN on tissue regeneration. A large number of different methods of the treatment of diabetic foot syndrome have been introduced, but in the course of further studies of the complex multifactorial pathogenesis of diabetes, new unresolved problems arise [38]. The incidence of diabetes is increasing worldwide and the number of complications is increasing. This determines the need for the introduction of new methods of the treatment.

\section{Conclusion}

This study showed that wound healing was significantly accelerated in the combination treatment group (PDRN loaded in hydrogel) compared to the hydrogel-only group and the control group (no treatment).

In the studied models of healing full-thickness skin wounds against the background of induced diabetes mellitus, topical application of PDRN stabilized in CMC hydrogel showed an acceleration of the regeneration process in the damaged area. The rate of acceleration of wound healing in the group receiving only PDRN was significant compared to the control group, but in this regard, the difference between the groups receiving only hydrogel was less significant. In addition, when analyzing the number of blood vessels per unit area, the differences and changes in the number of blood vessels were significant in the combination treatment group compared to the control group and groups receiving only hydrogel on day 7 . In the group receiving only PDRN, significant differences in the number of fibroblasts were observed on day 7 compared to the control group and on day 14 compared to the group receiving only the hydrogel. In the group receiving only PDRN, significant differences in the number of collagen fibers were observed on day 21 compared with the control group and the group receiving only the hydrogel. Therefore, we can say that the use of PDRN accelerates angiogenesis and proliferation of fibroblasts and collagen fibers. Moreover, there was an increase in the total number of blood vessels in the hydrogel-only treatment group. Thus, it is believed that angiogenesis is facilitated by cell migration due to the wet environment of the hydrogel. It is believed that the effective results in the combination treatment group were related to the fact that the hydrogel served as a scaffold to increase maintenance and expression, stimulate angiogenesis, and further accelerate wound healing. Since the hydrogel acts as a scaffold for PRP, it increases the expression of growth factors and helps in maintaining and accelerating wound treatment.

In this study, the combination therapy of PDRN and hydrogel resulted in a more effective acceleration of diabetic wound healing. The hydrogel is believed to act as a scaffold for PDRN, resulting in increased fibroblast expression and collagen production and accelerated angiogenesis.

\section{Limitations}

This research has limitations. Further work, including quantification and measurements, is needed to accurately assess the effects of VEGF expression. A more accurate assessment of the diffusion of PDRN from the hydrogel is also needed.

\section{References}

1. Armstrong DG, Boulton AJ, Bus SA. Diabetic foot ulcers and their recurrence. N Engl J Med. 2017;376(24):2367-75. https:// doi.org/10.1056/NEJMra1615439

PMid:28614678

2. International Diabetes Federation. IDF Diabetes Atlas. $8^{\text {th }}$ ed Brussels, Belgium: International Diabetes Federation; 2019.

3. Frykberg RG, Banks J. Challenges in the treatment of chronic wounds. Adv Wound Care (New Rochelle). 2015;4(9):560-82. https://doi.org/10.1089/wound.2015.0635 PMid:26339534

4. Jones RE, Deshka S, Longaker MT. Management of Chronic wounds-2018. JAMA. 2018;320(14):1481. https://doi.org/10.1001/ jama.2018.12426 PMid:30326512

5. Clark RA. The Molecular and Cellular Biology of Wound Repair Disorders, Pathophysiology, Pharmacology and Therapeutics: An Update. Germany: Springer; 2013. p. 494-7.

6. Galkowska H, Wojewodzka U, Olszewski WL. Chemokines, cytokines, and growth factors in keratinocytes and dermal endothelial cells in the margin of chronic diabetic foot ulcers. Wound Repair Regen. 2006;14:558-65. https://doi. org/10.1111/j.1743-6109.2006.00155.x PMid:17014667

7. Falanga V. Wound healing and its impairment in the diabetic foot. Lancet. 2005;366:1736-43. https://doi.org/10.1016/ 
S0140-6736(05)67700-8

\section{PMid:16291068}

8. Kwon TR, Han SW, Kim JH, Lee BC, Kim JM, Hong JY, et al. Polydeoxyribonucleotides improve diabetic wound healing in mouse animal model for experimental validation. Ann Dermatol. 2019;31(4):403-13. https://doi.org/10.5021/ad.2019.31.4.403 PMid:33911618

9. Lipsky BA, Aragón-Sánchez J, Diggle M, Embil J, Kono S, Lavery L, et al. IWGDF guidance on the diagnosis and management of foot infections in personswith diabetes. Diabetes Metab Res Rev. 2016;32(1):45-74. https://doi.org/10.1002/dmrr.2699 PMid:26386266

10. Morgan C, Nigam Y. Naturally derived factors and their role in the promotion of angiogenesis for the healing of chronic wounds. Angiogenesis. 2013;16(3):493-502. https://doi.org/10.1007/ s10456-013-9341-1

PMid:23417553

11. Kolluru GK, Bir SC, Kevil CG. Endothelial dysfunction and diabetes: Effects on angiogenesis, vascular remodeling, and wound healing. Int J Vasc Med. 2012;2012:918267. https://doi. org/10.1155/2012/918267

PMid:22611498

12. Squadrito F, Bitto A, Irrera N, Pizzino G, Pallio G, Minutoli L, et al. Pharmacological activity and clinical use of PDRN. Front Pharmacol 2017;8:224. https://doi.org/10.3389/fphar.2017.00224 PMid:28491036

13. Shin J, Park G, LeeJ, BaeH. The effect of polydeoxyribonucleotide on chronic non-healing wound of an amputee: A case report. Ann Rehabil Med. 2018;42(4):630-3. https://doi.org/10.5535/ arm.2018.42.4.630

PMid:30180535

14. Chung KI, Kim HK, Kim WS, Bae TH. The effects of polydeoxyribonucleotide on the survival of random pattern skin flaps in rats. Arch Plast Surg. 2013;40:181-6. https://doi. org/10.5999/aps.2013.40.3.181 PMid:23730590

15. Jeong W, Yang CE, Roh TS, Kim JH, Lee JH, Lee WJ. Scar prevention and enhanced wound healing induced by polydeoxyribonucleotide in a rat incisional wound-healing model. Int J Mol Sci. 2017;18(8):1698. https://doi.org/10.3390/ ijms 18081698

PMid:28771195

16. Lee WY, Park KD, Park Y. The effect of polydeoxyribonucleotide on the treatment of radiating leg pain due to cystic mass lesion in inner aspect of right sciatic foramen: A CARE compliant case report. Medicine. 2018;97(41):e12794. https://doi.org/10.1097/ MD. 0000000000012794

PMid:30313106

17. Bitto A, Polito F, Irrera N, D'Ascola A, Avenoso A, Nastasi G, et al. Polydeoxyribonucleotide reduces cytokine production and the severity of collagen-induced arthritis by stimulation of adenosine A2A receptor. Arthrit Rheum. 2011;63(11):3364-71. https://doi.org/10.1002/art.30538

PMid:21769841

18. Kim S, Kim J, Choi J, Jeong W, Kwon S. Polydeoxyribonucleotide improves peripheral tissue oxygenation and accelerates angiogenesis in diabetic foot ulcers. Arch Plast Surg. 2017;44(6):482-9. https://doi.org/10.5999/aps.2017.00801 PMid:29076318

19. Guizzardi S, Uggeri J, Belletti S, Cattarini G. Hyaluronate increases polynucleotides effect on human cultured fibroblasts. J Cosmet Dermatol Sci Appl. 2013;3(1):124-8.

20. Minutoli L, Arena S, Bonvissuto G, Bitto A, Polito F, Irrera $\mathrm{N}$, et al. Activation of adenosine $\mathrm{A} 2 \mathrm{~A}$ receptors by polydeoxyribonucleotide increases vascular endothelial growth factor and protects against testicular damage induced by experimental varicocele in rats. Fertil Steril. 2011;95(4):1510-3. https://doi.org/10.1016/j.fertnstert.2010.07.1047

PMid:20797711

21. Wang C, Varshney RR, Wang DA. Therapeutic cell delivery and fate control in hydrogels and hydrogel hybrids. Adv Drug Deliv Rev. 2010;62(7-8):699-710. https://doi.org/10.1016/j. addr.2010.02.001

PMid:20138940

22. Chattopadhyay S, Raines RT. Collagen-based biomaterials for wound healing. Biopolymers. 2014;101(8):821-33. https://doi. org/10.1002/bip.22486

PMid:24633807

23. Chang SC, Zhang L. Cellulose-based hydrogels: Present status and application prospects. J Carbohydrate Polymers. 2011;84(1):40-53.

24. Parenteau-Bareil R, Gauvin R, Berthod F. Collagen-based biomaterials for tissue engineering applications. Materials. 2010;3(3):1863-87. https://doi.org/10.3390/ma3031863

25. Laçin NT. Development of biodegradable antibacterial cellulose based hydrogel membranes for wound healing. J. Biol Macromol. 2014;67:22-7.

26. Kabir MF, Sikdar PP, Haque B, Bhuiyan MA, Ali A, Islam MN Cellulose-based hydrogel materials: Chemistry, properties and their prospective applications. Prog Biomater. 2018;7(3):153-74. https://doi.org/10.1007/s40204-018-0095-0 PMid:30182344

27. Principles of Laboratory Animal Care. United States: NIH Publication; 1985.

28. Heilborn JD, Nilsson MF, Kratz G, Weber G, Sørensen O, Borregaard $\mathrm{N}$, et al. The cathelicidin anti-microbial peptide LL-37 is involved in re-epithelialization of human skin wounds and is lacking in chronic ulcer epithelium. J Invest Dermatol. 2003;120(3):379-89. https://doi.org/10.1046/j.1523-1747.2003.12069.x PMid: 12603850

29. Salehi-Lalemarzi H, Shanehbandi D, Shafaghat F, AbbasiKenarsari $\mathrm{H}$, Baradaran $\mathrm{B}$, Movassaghpour AA, et al. Cloning and stable expression of cDNA coding for platelet en-dothelial cell adhesion molecule-1 (PECAM-1, CD31) in NIH-3T3 cell line. Adv Pharm Bull. 2015;5(2):247-53. https://doi.org/10.15171/ apb.2015.034

\section{PMid:26236664}

30. Hossain M, Qadri SM, Xu N, Su Y, Cayabyab FS, Heit B et al. Endothelial LSP1 modulates extravascular neutrophil chemotaxis by regu-lating nonhematopoietic vascular PECAM-1 expression. J Immunol. 2015;195(5):2408-16. https://doi. org/10.4049/jimmunol.1402225

PMid:26238489

31. Henning UG, Wang Q, Gee NH, Von Borstel RC. Protection and repair of g-radiation-induced lesions in mice with DNA or deoxyribonucleosidetreatments.MutationRes. 1996;350(1):247-54. https://doi.org/10.1016/0027-5107(95)00109-3

32. Tonello G, Daglio M, Zaccarelli N, Sottofattori E, Mazzei M, BalbiA. Characterization and quantitation of the active polynucleotide fraction (PDRN) from human placenta, a tissue repair stimulating agent. J Pharmacol Biomed Anal. 1996;14(11):1555-60. https:// doi.org/10.1016/0731-7085(96)01788-8 PMid:8877863

33. Xi C, Wu Z, Kun Z, Guohui L, Yang S, Ye S, et al. Treatment of chronic ulcer indiabetic rats with self assembling nanofiber gel encapsulated-polydeoxyribonucleotide. Am J Transl Res. 2016;8(7):3067-76.

PMid:27508027

34. Altavilla D, Squadrito F, Polito F, Irrera N, Calò M, Cascio PL, 
et al. Activation of adenosine A2A receptors restores the altered cell-cycle machinery during impaired wound healing in genetically diabetic mice. Surgery. 2011;149(2):253-61. https:// doi.org/10.1016/j.surg.2010.04.024

PMid:20570301

35. Galeano M, Bitto A, Altavilla D, Minutoli L, Polito F, Calò M, et al. Polydeoxyribonucleotide stimulates angiogenesis and wound healing in the genetically diabetic mouse. Wound Rep Reg. 2008;16(2):208-17. https://doi. org/10.1111/j.1524-475X.2008.00361.X

PMid:18318806

36. El-Sherbiny MI, Yacoub HM. Hydrogel scaffolds for tissue engineering: Progress and challenges. Glob Cardiol Sci Pract. 2013;2013(3):316-42. https://doi.org/10.5339/gcsp.2013.38 PMid:24689032

37. Grim C, Marozas IA, Anseth KS. Thiol-ene and photo-cleavage chemistry for controlled presentation of biomolecules in hydrogels. J Control Release. 2015;219:95-106. https://doi. org/10.1016/j.jconrel.2015.08.040

PMid:26315818

38. de Oliveira Gonzalez C, Costa TF, de Araújo Andrade Z, Medrado AR. Wound healing-a literature review. An Bras Dermatol. 2016; 91:5. https://doi.org/10.1590/abd1806-4841.20164741

PMid:27828635 